\title{
Monseñor Romero.
}

\section{Cristiano y salvadoreño}

\section{Jon Sobrino, \\ Centro de Reflexión Teológica, San Salvador.}

Desde su fundación en 1984, la Revista Latinoamericana de Teologia ha publicado varios arliculos sobre Monseñor Romero, cuya lista publicamos al final. En este artículo, y para celebrar el XX aniversario de su martirio, queremos decir una breve palabra sobre él, y nos hemos decidido por recordar lo que nos parece fundamental, principio y fundamento de muchas de las cosas de la vida, la fe, la praxis y el destino de Monseñor Romero. Monseñor fue un ser humano real, en un mundo y en una Iglesias reales, con una fe, una esperanza y un compromiso real. Esto es lo que resumimos al decir que Monseñor fue, simplemente y ante todo, salvadoreño y cristiano.

Recordamos esio para no relegar a Monseñor Romero a "la nada", como desearían muchos de los que en su día lo odiaron y dieron muerte, y de los que lodavía hoy no saben qué hacer con él. Pero lo recordamos, sobre todo, para no relegarlo a "la irrealidad, a la apariencia, al docetismo" — como explicaremos más adelante-, lo cual consideramos más peligroso que lo anterior, pues hace a Monseñor, en buena medida, inalcanzable $y$, a la postre, inofensivo.

Sobre estas cosas hablé. el 31 de julio de 1999, en un retiro dedicado a analizar "La espiritualidad de Monseñor". A continuación reproduzco, con muy pequeños cambios. lo que entonces dije, manteniendo el estilo oral.

\section{$* * *$}

En esta conferencia voy a recordar lo que más me impactó de la espiritualidad de Monseñor Romero, tal como me lo han pedido. Pero antes de comenzar el ańlisis digamos una palabra sobre espiritualidad, los problemas que veo en el término y por qué. 
He de confesar que la palabra "espiritualidad" me pone incómodo y hasta me da un poco de miedo. La razón es que espiritualidad viene de espíritu, y el espíritu es algo que no se ve y suele contraponerse a lo material e histórico. Por esa razón, la espiritualidad puede llevarnos, de alguna manera, a un mundo invisible, e incluso a un mundo irreal. El peligro es claro, siempre que se habla de espiritualidad, pero es especialmente trágico al hablar de la espiritualidad de Monseñor Romero, pues si algo no hizo Monseñor lue el vivir en un mundo irreal y desentenderse de la realidad salvadoreña. Todo lo contrario. Indudablemente, Monseñor tenía una íntima relación con Dios, "el gran Invisible", pero eso no lo llevó a confundir el mundo de la espiritualidad con el mundo de lo invisible, sino que lo llevó a encarnarse con profundidad y radicalidad extraordinarias en la realidad salvadoreña. Fue, cada vez más, un arzobispo, un cristiano y un salvadoreño real. La espiritualidad en modo alguno lo llevó a lo irreal.

Al final volveremos a la relación con Dios que tenía Monseñor, pero ahora quiero insistir en que no cayó en el peligro y en la trampa — típicos de muchas personas espirituales-, como ha sido frecuente en la historia de la Iglesia. Así lo denunciaba hace muchos años un autor francés: "porque no son de la tierra, creen que son del cielo; porque no aman a los seres humanos, creen que aman a Dios". Son palabras fuertes, pero útiles y necesarias, porque nos ponen en guardia contra una falsa espiritualidad.

¿Qué queremos decir, entonces, al hablar de la espiritualidad de Monseñor Romero, si eso no lo llevó a lo invisible y a lo irreal? En lo fundamental, queremos decir que Monseñor vivió ante Dios y ante los seres humanos, trabajo, sufrió y esperó con fuerza, con energía. Pues bien, esa fuerza y energía es lo que significa la palabra "espíritu". Monseñor Romero fue hombre espiritual, porque estaba lleno de la fuerza de Dios, del Espíritu de Dios. Y, de nuevo, para no caer en el peligro de volatilizar ese Espíritu, recordemos que ese Espŕritu es el Espírilu de Jesús, y no otro. Monseñor Romero fue modelado por la fuerza del Espíritu para parecerse a Jesús.

Si nos preguntamos ahora -antes de comenzar el análisis- de dónde sacaba Monseñor Romero esa fuerza y energía, cómo llegaba a estar en sintonía con el Espíritu de Jesús, se pueden decir varias cosas. Indudablemente, la oración, la lectura y la escucha de la palabra de Dios, fueron lugares importantes para empaparse de ese Espíritu. Pero oración y meditación pueden hacerse en muchos lugares y de muchas maneras. Lo específico de Monseñor, pienso yo, es que el lugar privilegiado de su oración y meditación fue la realidad salvadoreña, Ian llena de pecado y tan llena de gracia, tan llena de injusticia y tan Ilena de esperanza. Por decirlo en forma más humana, esa realidad fueron los pobres del pueblo salvadoreño. Ahi se ponía en contacto con Dios y ahí se dejaba empapar por el Espíritu, poriglafuerzzapde BDilosteca "P. Florentino Idoate, S.J." 
Monseñor se dejó mover por el Espírilu de Dios, dejándose conmover por la realidad salvadoreña, por el terrible sulrimiento, el heroico compromiso y la increíble esperanza de los pobres. Dios y el evangelio no lo hicieron desentenderse de la realidad, no se convirtieron en una especie de droga para adormedecerse ante ella, sino todo lo contrario. Dios y el evangelio lo remitieron a la realidad de su pueblo, y allí sacó luz para mejor conocer a Dios, y sacó luerza y energía para poner en práctica el evangelio. Monseñor Romero fue salvadoreño y cristiano "rcal", y eso, creo yo, fue lo más profundo de su espiritualidad.

Sobre esta espiritualidad de Monscñor voy a decir cuatro cosas, siguiendo el esquema de la vida de Jesús: encarnación, misión, cruz y resurrección. Espiritualidad fue vivir en la realidad esos cuatro momentos constitutivos de la vida de Jesús.

\section{Monseñor Romero, como Jesús, fue "real" en su encarnación en la realidad salvadoreña tal cual ésta era}

Creo que todos recordamos los tiempos en que para ensalzar a alguien se solía decir que era muy "humano", o "cristiano", o "auténtico"... Pero creo que eso no basta, y ni siquiera basta decir que "es un santo, muy espiritual". La razón es que se pudiera ser lodo esto y no ser real; en nuestro caso, no ser salvadoreño. Por ejemplo, en un país en que habido persecuciones, si éstas no nos salpican, nos podrán decir las cosas bellas que hemos mencionado, pero no somos reales, sino irreales.

Recordemos ahora a Monscñor Romero y preguntémonos qué era en su tiempo la realidad $-y$ las cosas no han cambiado del todo. En El Salvador había anowim - los encorvados bajo el peso de una carga, que dice la Escrilura-, había gente pobre, para quien vivir era su máxima tarea, y su destino más cercano era muchas veces morir, o de hambre o de represión. Había - y hay - los que no tenían dignidad, los insignificantes, los que no cuentan, los excluidos. Había los silenciados, los que no tenían palabra. Había los impotentes, que no tenían poder para hacer valer sus derechos elementales. Había los despreciados, porque no cumplían con los requisilos de la cultura que se nos impone.

Esa era la realidad de entonces, y a todos estos grupos de personas, el neoliberalismo añade hoy los inexistentes, los que ni siquiera son ya mano de obra barata, porque no tienen empleo, ni se piensan las cosas para que realmente lo Ileguen a tener -además de que ha crecido la conciencia de la opresión, ocultada por siglos, de mujeres, niños, razas... Y en tiempos de Monseñor Romero también había - aunque hoy esto no se dé de la forma aberrante de entonces- la represión inhumana y crucl. Como él decía: "Machetear, torturar,

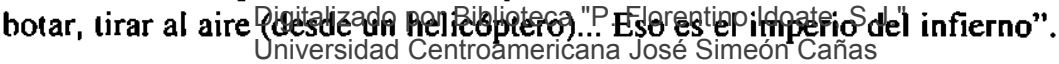


La pregunta por la espiritualidad de Monseñor Romero consiste, pues, en saber qué hizo, el hombre y el cristiano que era, en csa realidad. Y empecemos recordando lo que no hizo. Por sencillo que parezca decirlo, lo que Monseñor nunca hizo fue desentenderse de esa terrible realidad. Para esclarecer esto pudiéramos comenzar reconociendo sus limilaciones, incluso sus posibles errores, pero lo que nunca hizo Monseñor fue desentenderse de la realidad en que vivía. Eso lue el primer paso de lo que los cristianos llamamos la encarnación. Y digamos de pasada que cuando hablamos de la carne que asumió Crislo en la cncarnación, el evangelio no habla simplemente de "carne", sino de sarx, es decir, de "lo débil de la carne". Lo mismo hizo Monseñor Romero: no se encarnó, simplemente, en la realidad salvadoreña, sino en lo débil de ella, en el dolor, en la pobreza, en el sufrimiento, en la opresión y la represión de los pobres.

He comenzado de esta lorma el análisis de la espiritualidad de Monseñor Romero, porque, en mi opinión, una de las cosas que más peligra hoy en la Iglesia, y en la salvadoreña, es la falta de encarnación en la realidad. El peligro es caer en la irrealidad, y acabar no viviendo en este mundo, no haciendo nuestras las realidades de los pobres del país. La Iglesia podrá decir que lienc otros ámbitos de realidad, lo cual es obvio: el ámbito de la evangelización, de la liturgia, de lo doctrinal y de lo canónico... Acepla que puede actuar en el ámbito de lo social, pero no en el de lo político. Repite que, en definitiva, lo suyo es traer la salvación de Dios... Pero lo que me preocupa es que, apelando a éstas o semejantes razones, más o menos válidas, la Iglesia acabe distanciándose de la realidad salvadoreña.

Veámoslo en un ejemplo relativamente reciente, que lo menciono con el respelo que merecen estas cosas, pero también por la capacidad que tienen para iluminar el tema de la encarnación. En 1996, nos visitó el Santo Padre. Más allá de la mezcla, comprensible e inevitable, de devoción y euforia, de mensaje cristiano y de folclore, la pregunta es, cómo y dónde apareció la realidad del país en esa visita; es decir, dónde estaban los pobres. Ciertamente, estaban en las aceras a lo lago del recorrido papal, pero estaban más como telón de fondo que como lo central de la realidad. La realidad más real, su pobreza, sus sufrimientos, y también sus esperanzas y sus gozos, no aparecían como tema central. Al parecer, según los organizadores de la visita del Santo Padre, que apareciese la realidad no era, en delinitiva, cosa importante. Ciertamente, no lo más importante. $Y$ de esta forma, aun sin pretenderlo, la Iglesia daba la imagen de muchas cosas: de buena organizadora, de cercana a los dirigentes del país, a los medios, pero no daba la imagen de una Iglesia salvadoreña, una Iglesia de los pobres, una Iglesia real.

Pues bien, con Monseñor Romero, las cosas no eran así. Lo apasionó la

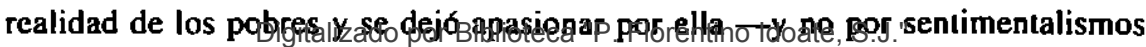

Universidad Centroamericana José Simeón Cañas 
superficiales, sino porque en ella vio lo último del dolor y de la esperanza, y lo último de su propia le: la presencia de Dios y de Jesús. Suelo decir, porque mucho me impacıa, que de aquella Iglesia de Monseñor Romero se podrán decir muchas cosas. Se podrá decir que aquella Iglesia tenía limitaciones, que cornelía crrores y aun pecados. Pero lo que no se podrá decir de la Iglesia de Monseñor Romero es que no era salvadoreña $-y$ no en un sentido populista-, que no era "real". Las mayorías de pobres, campesinos y obreros, no sintieron a esa Iglesia ajena a ellos, no la vieron como cosa distinta a cllos. La vieron como suya, salvadoreña, real.

Esto lo expresaba Monseñor Romero ante todo en su quehacer cotidiano. Pero de vez en cuando se le escapaban frases de audacia exirema y de gran belleza para expresar su gran ilusión: que la Iglesia luera salvadoreña. Así, Monseñor Romero hacía alirmaciones como ésta, que impactan hasta el día de hoy. "Me alegro, hermanos, de que la Iglesia sea perseguida". Alguien pudiera pensar que éstas son las palabras de un místico, de un santo. Pero no. En ellas habla - simplemente - un cristiano y un salvadoreño. Pero, además, da la razón de esa paradójica alegría: la persecución ocurre "por tratar de encarnarse en el interés de los pobres". Monseñor Romero se alegraba de la persecución no por causa de misticismos precipitados, sino porque eso hacía a la Iglesia una Iglesia salvadoreña, una Iglesia real. Así, en palabras más fuertes todavía decía: "sería triste que en una patria donde se está asesinando tan horrorosamente no contáramos entre las víctimas también a los sacerdotes".

Estas son frases de un gran cristiano y, por así decirlo, bastarían para canonizarlo o nombrarlo doctor de la Iglesia. Pero lo importante no es la genialidad y la maravilla de la cormulación, sino la honda convicción de Monseñor Romero, su pasión por "ser real". En efecto, los sacerdotes asesinados son el testimonio de una Iglesia encarnada en los problemas del pueblo. No eran perfectos, reconocía Monseñor, tenian sus fallas. pero fueron asesinados por vivir en y querer construir una Iglesia salvadoreña, una Iglesia real.

Y es importante recalcar también, no sólo para superar cualquier indicio de masoquismo, sino para comprender la pasión de Monseñor Romero por una Iglesia real, que quería que esta Iglesia expresase también lo positivo de la realidad, los gozos y las esperanzas de los pobres, como dice el comienzo de la Gaudium et Spes, pero con seriedad. Cuando veía la fortaleza, el aguante del pueblo, decía entonces. dirigiéndose a los cristianos: "Si alguna vez nos quitaran la radio, nos suspendieran el periódico, no nos dejaran hablar, nos mataran a codos los sacerdotes y al obispo también, y quedaran ustedes, un pueblo sin sacerdotes, cada uno de ustedes tiene que ser un micrófono de Dios, cada uno de ustedes tiene que ser un mensajero, un profeta".

Estas palabras de Monseñor Romero sobre su Iglesia reflejan muy bien lo

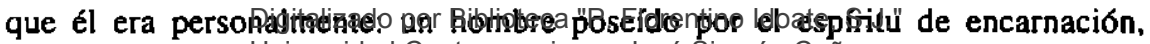
Universidad Centroamericana José Simeón Cañas 
espírilu de solidaridad con la realidad y sus pobres. Pienso que si de algo se hubiese avergonzado Monseñor hubiese sido de una Iglesia a la que no la salpicase la realidad salvadoreña. Y nunca hubiera argumentado, aunque sólo fuese en su interior, como si la Iglesia csluviese más allá de los peligros de la realidad. Hubiese denunciado este docelismo elicaz, que a veces se da por descontado, y se podría formular con palabras como éstas: "Aunque injusto y trisle, es normal que a los sindicatos les quiten los micrófonos y pongan bombas, que a los campesinos los opriman y repriman. Lo que no sería normal es tratar así a la Iglesia, porque no somos como los demás". Monseñor Romero, por el contrario, diría: "¡Me alegro de que nos quiten los micrófonos! Somos como los demás, y vamos a mostrar el mismo aguante y la misma fortaleza que los demás".

Termino esta reflexión. La lglesia de Monseñor Romero, con él a la cabeza, fue una lglesia real. Y a la inversa, una Iglesia que no es pobre en liempo de pobreza, que no es perseguida en tiempo de persecución, que no es asesinada en tiempo de asesinatos, que no se compromele en tiempo de compromiso y no anima a él en tiempo de indiferencia, que no tiene esperanza en tiempo de esperanza, y no anima a ella en tiempo de desencanto, simplemente no es una Iglesia real. Quiźs puede parecer muy "espiritual" por otros capítulos, si se me permite la ironía, pero no tiene el "espíritu de realidad" que tenía Monseñor $-y$ Jesús de Nazaret.

\section{Monseñor Romero, como Jesús, llevó a cabo la misión de evangelizar a todo un pueblo, a toda la realidad}

Monseñor Romero evangelizó con la palabra, anunciando la buena noticia del amor de Dios al pobre, denunciando al opresor, escribiendo cartas pastorales para iluminar al país. Evangelizó con las obras, buscando el diálogo por la paz, apoyando el trabajo del Socorro Jurídico, del Secretariado Social, abriendo los primeros refugios en los albores de la guerra. Evangelizó con su persona, con su modo de ser, que fue un eu-aggelion, buena noticia, para las mayorías del pals y para muchos otros fuera de él. Todo esto es bien conocido. Lo que hay que recalcar, en ténninos de espiritualidad, es, en primer lugar, que Monseñor hizo todo ello con espíritu de misericordia. Y en segundo lugar, en lo que quiero fijarme ahora, con misericordia hacia todo un pueblo. Monseñor Romero buscó la salvación de todo el pueblo.

Recuerdo esto porque hoy abundan movimientos eclesiales que quieren traer salvación a matrimonios, a jóvenes, a universitarios - como también intentamos hacerlo en la UCA-, y bien sabemos cuán necesario es todo ello. Pero hay que estar claros que la realidad es mayor. La realidad los incluye, por supuesto, y expresa cuán importantes son. En nuestros países, por ejemplo, la juventud es

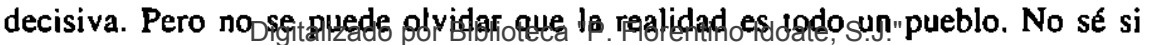

Universidad Centroamericana José Simeón Cañas 
este lenguaje sucna ya a cosa pasada o a ingenuo, pues mucho han cambiado las cosas en la Iglesia desde el tiempo de Monscñor Romero. Pero si queremos recordar a Monseñor, tenemos que recordar a las mayorías populares, al pueblo.

Ignacio Ellacuría, quien era buen conocedor de Monseñor Romero, y todo menos ingenuo, cuando, poco después de la muerte de Monseñor, le pidieron escribir un artículo sobre él, comenzó con cslas palabras: "Monseñor Romero, un enviado de Dios para salvar a su pueblo". Por lo que loca a la misión de la Iglesia, eso significaba que Monseñor quería trabajar para salvar al pueblo. Y por lo que toca a la espiritualidad, signilica que tenía aliento para mirar a la totalidad del pueblo.

"Estas homilías, decía, quieren ser la voz de los sin voz", es decir, de las mayorías, del pueblo. Cuando veía aberraciones y desmanes, sufrimientos sin cuento en el país, decía: "sobre estas ruinas hrillará la gloria del Señor". Cuando, con compasión, miraba a la gente, decía como Jesús: "están como ovejas sin pastor".

¿Qué quiero decir con esto? En el seguimiento de Jesús y en la misión de la Iglesia, Monseñor Romero tenía presente a las mayorías, a la totalidad de la realidad. El no podía salvarla solo, por supuesıo. Tampoco la Iglesia. Pero no cayó en lo que me parece es un triple peligro. El primero es delimitar los ámbitos de la evangelización de la Iglesia, cuidando mucho de no traspasar el propio ámbito eclesial, reduciéndose a él y empequeñeciendo la misión: "esto es político, esto no es político", como si de esa manera, precisando lo que es la realidad en base a definiciones, desapareciera la responsabilidad primaria de la Iglesia, y de todo ser humano, de salvar a la realidad. El segundo es reducir y empequeñecer el horizonte de la misión. contentándose con hacer cosas buenas, salvando así la responsabilidad eclesial. Y el tercero es pactar con el "pequeño relato", en el que no caben totalidades, como pueblos crucificados, esperanzas y trabajos para bajarlos de la cruz. Dicho en este lenguaje, Monseñor Romero luvo el espíritu de los grandes relatos.

Monseñor Romero no era apocado, de lo pequeño, del sálvese lo que se pueda. Como arzobispo, sabía muy bien lo que le tocaba hacer y lo que no le tocaba hacer - profesionalmente, por así decirlo. Pero el horizonte de su misión era claro: hay que salvar todo y a todos. En este sentido, hay que decir que Monseñor Romero era hombre de espírilu grande, hombre de aliento a la hora de decidir qué hacer. Sus cartas pastorales $-y$ hay que recordar que desde entonces no se ha escrito una carta pastoral importante sobre el país- miraban a los problemas con repercusión para toda la población. Sus denuncias, como todos sabemos, tenían alcance global -aunque mencionara también, precisamente por ello, todos los casos de violación de los derechos humanos. Sus homilías dominicales fueron ejemplo sin paralelo de una pastoral "masiva",

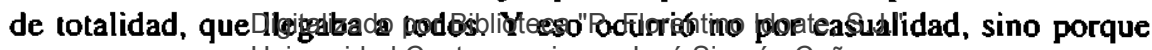
Universidad Centroamericana José Simeón Cañas 
así lo pretendía él, lo cual le llevó a cumplir, por así decirlo, con las condiciones que le imponía esa pastoral masiva: seria preparación de la homilía en su parte bíblica para que iluminase en verdad la realidad del país, conocimiento de los hechos importantes del país, credibilidad en sus palabras, decisión a seguir "siempre". a pesar de las calumnias, de muchas interlerencias, de la destrucción de la cmisora...

Qucría evangelizar las estructuras — cosa de la que ya casi no se habla-, cambiar la economía, la política, las instituciones del derecho, de la salud, de los medios... Y queria cambiar también — cvangelizar- la estructura eclesial, con sus curias, parroquias, congregaciones religiosas, instituciones educativas, relaciones inernas. Y cuando vio problemas graves en el país, violencia, la siluación de las organizaciones populares, y, al linal de su vida, la inminencia de la guerra, los abordó con responsabilidad y teniendo ante sí al país. A veces amenazaba con el castigo, como los profetas de Israel, pero no a este o a aquel, sino a toda la clase opresora: "ustedes, los ricos, quítense los anillos, porque, si no, les van a cortar la mano" (cila, por cicrlo, de Pablo VI).

Monseñor Romero vio también que. en los peligros que he citado, existen los peligros opuestos: meterse en lo político como esfera del poder, querer abarcar lanto que se termina por no hacer nada. Pero no vio esos peligros como el problema mayor. No se dejó encerrar en una sacristía, ni en una pastoral, ni en una misión con horizontes pequeños.

Y todo esto lo conjugaba, con creatividad excepcional, con una cercanía real al pueblo concreto en las comunidades. Hacía sus visitas pastorales, y con ellas cubría la realidad de toda la arquidiócesis, pero no perdía la perspectiva total del país. Si Monseñor Romero iba a tal pueblo o cantón, a tal lugar, eso tenía una proyección mayor. Si hablaba por radio, muchas comunidades participaban de lo que decía. Cuando abrió un refugio - por cierto en el edificio del Seminario-. hizo mucho más que abrir "un" refugio: puso en marcha todo un movimiento de refugios.

¿Qué quiero decir con todo esto? Monseñor Romero, indudablemente, tenía una idea sobre lo que era evangelizar - y recuerdo que en 1977 organizó un scminario para sacerdotes sobre la Evangelii numtiandi de Paulo VI. Lo más novedoso fue para mí que quiso evangelizar a la totalidad del país, a todos, personas, grupos sociales y estructuras. Y quería evangelizar un país donde había una opresión y represión espantosas, secuestros, desaparecidos, muertos, donde había pobreza, injusticia, pero donde también había esperanza, compromiso, fortaleza, fidelidad, martirio... Ya lo hemos dicho. Monseñor fue hombre de aliento, de parresía paulina. Evangelizar significaba "salvar a un pueblo". Y de eso hay ahora déficil en la Iglesia. 


\section{Monseñor Romero cargó con el peso de la realidad: como Jesús, murió en la cruz}

Esto es bien conocido, y no es necesario detenerse mucho en ello. Sólo quiero aclarar que la espiritualidad de Monseñor no fue una espiritualidad del sufrimiento, entendida ascética o místicamente, sino una espiritualidad de honradez con la realidad, y, por ello, de cargar con ella. Fácilmente Monseñor pudo haber suavizado sus denuncias, pudo haber llegado a arreglos, pudo haber abandonado el país - y lo hubiese podido justificar. Pero la honradez lo llevó a cargar con esa realidad que pesa y a no deshacerse de ella. Sobre todo, a no invocar a Dios y al evangelio, para rehuir la carga.

Como he dicho, esto no hace falta explicarlo mucho. Sólo quiero recordar que cargar con la cruz no es la expresión de nada sublime, sino que es lo más obvio de lo obvio, si uno quiere ser honrado con la realidad. Digo esto porque esta convicción ha cambiado y, en general, hay déficit en el pafs, en los políticos y también en la Iglesia, de esa honradez y disponibilidad para cargar con el peso la realidad.

Suelen decir que hoy las cosas han cambiado, y es cierto que hay novedades importantes. Pero en el país no ha cambiado la pobreza y la injusticia, como realidades fundamentales -aunque cambien sus formas-, ni siquiera la violencia se ha reducido drásticamente. $Y$ a nivel mundial los informes de Naciones Unidas muestran anualmente la aberración en que está sumido el planeta. No ha cambiado, en lo sustancial, el conflicto social, ni la necesidad de ser desenmascarado $-\mathrm{y}$ resuelto, por supuesto. Por esa razón, tampoco ha cambiado la necesidad de introducirse en ese conflicto. Lo que ha cambiado en muchos lugares, y también en el país, es la disponibilidad y la decisión a ver y decir la verdad de las cosas y a introducirse en el conflicto.

En tiempo de Monseñor Romero, la Iglesia estaba en conflicto con los poderes opresores por defender a las mayorías de la opresión y la represión. Sabemos que esa aclitud produce muchos sufrimientos y que a la larga es difícil de mantener - y no todas las situaciones a lo largo de la historia son igualmente graves, por supuesto. Pero parece que ahora se debiera rehuir, como por principio, todo lo que sea conflicto, como si se hubiese descubierto algo mejor: un modo de ser Iglesia que puede vivir sustancialmente en armonía con otros poderes de este mundo, aun cuando éstos siguen produciendo víctimas.

Cuando eso ocurre, por así decirlo, la realidad ya no pesa no es onerosa, y no hay que cargar con ella. Pero entonces resuenan las palabras de Monseñor Romero: "una Iglesia que no sufre persecución, sino que está disfrutando los privilegios y el apoyo de la lierra, esa Iglesia tenga miedo, no es la verdadera Iglesia de Jesucristo". El decía estas palabras en tiempos en que la persecución

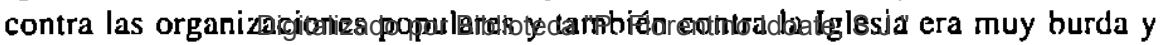


despiadada, y ahora no es así. Pero pensar que no sufrir persecución es más cristiano, que la armonía de la Iglesia con los poderes de este mundo es lo más descable, es un error, visto desde el evangelio y visto desde Monseñor Romero.

En la sociedad hay muchos confliclos reales, y la Iglesia está ante muchos conflictos potenciales, si lleva a cabo su misión de denuncia profética y de opción por los pobres. Para hacerlo, necesita un espíritu como el de Monseñor Romero, espíritu de honradez con la realidad, espíritu de fortaleza para introducirse en el conflicto y espíritu de entrega para cargar con el peso de esa realidad. Eso es hoy cargar con la cruz.

\section{Monseñor Romero se dejó cargar por la realidad y experimentó la gracia de vivir ya como resucitado}

Poco antes de morir, Monseñor Romero dijo estas conocidas palabras: "si me matan resucitare en cl pueblo salvadoreño". Y de varias formas se pucde decir que eso ha ocurrido: Monseñor vive en la esperanza, en la celebración de personas y coinunidades, y vive sobre todo en muchos corazones salvadoreños $-y$ de todo el mundo- cuando se deciden a vivir como él, como Jesús.

Pero, hablando de la espiritualidad de Monseñor, quisiera terminar con unas reflexiones que no suelen hacerse normalmente. Es cierto que la realidad es dura y que con ella hay que cargar, pero la realidad también carga con nosotros y nos ayuda a caminar en la historia. En palabras cristianas, en la realidad hay también don y gracia, algo que se nos da. En palabras todavía más audaces, en esta realidad podemos vivir ya como resucitados. Cuando la historia no ata $y$ triunfamos sobre lo que en ella hay dc esclavizante, retlejamos de alguna forma lo que de triunto hay en la resurrección de Jesús. Eso expresa plenitud, y se muestra cuando en el seguimiento de Jesús - centrado en el amor- aparece la libertad, el gozo y la esperanza. Eso es lo que apareció en Monseñor Romero.

La realidad - la gente, con su ejemplo de compromiso y generosidad- empujó a Monseñor Romero a actuar con libertad, a ser hombre libre. No se trataba de la libertad liberal, proclive al egoísmo, sino que para Monseñor Romero, como para Jesús, libertad significaba que nada va a ser obstáculo para hacer el bien. Ese es un hombre libre. Y esa libertad le provenía de la gente. El sufrimiento que veía en su pueblo y el cariño que su pueblo le mostraba, desarmaba a Monseñor, lo hacía libre. De ahí que pudiera decir como Jesús: "nadie me quila la vida, sino que yo la doy libremente".

La realidad - de nuevo, la gente sencilla, con su cariño- lo llevó también al gozo de vivir y servir. Monseñor era nervioso por carácter, débil e intranquilo a veces. Pero creo que - paradójicamente, y en medio de tantos problemas- vivió con paz y gozo. A veces se le nolaba en la sonrisa de su rostro,

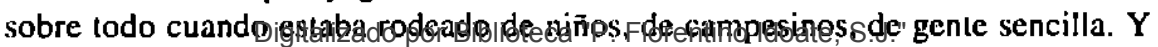


una vez lo puso en estas bellas palabras: "con este pueblo no cuesta ser buen pastor". Indudablemente, le costó mucho. Al cargar con el pueblo, tuvo que cargar con la cruz. Y sin embargo, el pueblo también cargó con él. Por ello, Monseñor Romero luvo que sufrir, pero no cayó en la tristeza. Como Jesús, sintió el profundo gozo de que los pequeños entendieron el misterio del reino de Dios.

Y por último, la esperanza. Son conocidas sus denuncias de las aberraciones del país, que parecían llevar a la impotencia y a la resignación. Sin embargo, Monseñor Romero fue hombre de esperanza: "muchas veces me lo han preguntado: ¿hay salida? Y yo, lleno de fe, no sólo una fe divina, sino también humana, digo: ¡sí hay salida!". Monseñor triunfó sobre la resignación, la desesperanza y el desencanto.

De esta realidad salvadoreña que él vivió con honradez, estando en ella, queriéndola cambiar radicalmente, cargando con su peso, surgí también la gracia, la libertad, el gozo, la esperanza. De esa manera Monseñor vivió ya como resucitado en la historia. Y eso es muy importante recordarlo, cuando en las iglesias no abunda la liberlad, el gozo y la esperanza. Es la espiritualidad de la gracia, del dejarse agraciar.

Estos son, a mi modo de ver, los rasgos principales de la espiritualidad de Monseñor Romero. Lo que he querido recalcar es que estos rasgos son actitudes, convicciones, práclicas, relacionadas con la realidad.

Quizás pueda extrañar este modo de enfocar la espiritualidad, en lugar de haber analizado su relación con Dios. Ahora sólo puedo decir que para Monseñor Romero Dios fue bien real. En el fondo del corazón - en "la celda del corazón", como él decía- estaba Dios. De eso no lengo ninguna duda. Sólo quisiera añadir, para terminar, que percibir que Dios está en el corazón de una persona es, por una parte, un misterio. Pero, por la otra, se echa de ver en el modo de estar la persona en la realidad, en lo que hace con ella, en la disponibilidad a cargar con ella y a dejarse cargar por ella. Cuando esa "cxterioridad" es como la de Jesús, entonces es que en el corazón de la persona, en su "interioridad", está el Dios de Jesús.

Monseñor Romero, salvadoreño y cristiano. Ojalá lo sigamos viendo así. Y ojalá no separe el hombre lo que Dios ha unido: un Monseñor en quien tomó la palabra lo salvadoreño y lo cristiano, lo mejor del país y lo mejor de la Iglesia, "sin celos" lo uno de lo otro, sino "llevándose" lo uno a lo otro. 


\section{Artículos sobre Monseñor Romero en la Revista Latinoamericana de Teologia}

Cardenal, Rodolfo, "En lidelidad al evangelio y al pueblo salvadoreño. El diario pastoral de Monseñor Romero", 4 (1985), pp. 3-81.

Cardenal, Rodolio, "En fidelidad al evangelio y al pueblo salvadoreño. El diario pastoral de Monseñor Romero. Parte linal", 9 (1986), pp. 225-245.

Revista Latinoamericana de Teología. "El último retiro espiritual de Monseñor Romero", 13 (1988), pp. 3-11.

Sobrino, Jon, "Mi recuerdo de Monseñor Romero", 16 (1989), pp. 3-44.

Revista Latinoamericana de Teología, "Décimo aniversario de Monseñor Romero",19, (1990), pp. 3-4.

Ellacuría, Ignacio, "Monseñor Romero un enviado de Dios para salvar a su pueblo", 19 (1990), pp. 5-10.

Casaldáliga, Pedro, "Un santo de todos y para toclos", 19 (1990), pp. II-I5.

Sobrino, Jon, "Monseñor Romero: diez años de tradición". 19 (1990), pp. 17-39.

Cavada Diez, Miguel, "Predicación y profecía. Análisis de las homilías de Monseñor Romero", 34 (1995), pp. 3-36.

Cavada Diez, Miguel, "La predicación como prolongación del proyecto salvífico de Cristo en las homilías de Monseñor Romero", 38 (1996), pp. 99-139.

Cavada Diez, Miguel, "La autoridad en la Iglesia. Palabra y testimonio de Monseñor Romero", 40 (1997), pp. 3-16.

De Sivatte, Rafael, "Monseñor Romero, los profetas de Israel y los ídolos: la religión, las potencias extranjeras, las armas, el poder", 41 (1997), pp. 173192.

Sobrino, Jon, "Reflexiones sobre el proceso de canonización de Monseñor Romero", 43 (1998), pp. 3-15.

De Sivalte, Rafael, "Monseñor Romero y los profetas de Israel: el ídolo de la riqueza y el Dios de la vida", 43 (1998), pp. 17-33.

Cavada Diez, Miguel, “Monseñor Romero y Medellín”, 45 (1998), pp. 231-250.

Cavada Diez, Miguel, "Monseñor Romero y los mártires", 48 (1999), pp. 215 236. 